Gut, 1964, 5, 271

Methods and techniques

\title{
The use of Bisacodyl suppositories in preparation for sigmoidoscopy
}

\author{
I. LYNNEVANS ${ }^{1}$ \\ From St. Mary's Hospital, London, and West Middlesex Hospital, Isleworth
}

EDITORIAL SYNOPSIS An excellent view can often be obtained without any preparation, but if faeces obscure the view the immediate use of a rectal suppository may enable a complete sigmoidoscopic examination to be made.

The sigmoidoscope has been an essential adjunct to digital and radiological examination of the lower bowel since Bardenheuer first invented the instrument in 1863 (Norbury, 1949). Sigmoidoscopy permits the diagnosis and treatment of many disorders of the bowel, while it is equally valuable for excluding organic lesions in patients with psychological disturbances. In particular almost $80 \%$ of cancers of the large bowel lie within reach of the sigmoidoscope (Smiddy and Goligher, 1957).

The main object of sigmoidoscopy is to inspect the lining of the bowel which should therefore be as empty as possible for the examination. Though good views are usually obtained without preparation of the patient, it is often necessary in other cases to empty a loaded rectum by artificial means to carry out a thorough examination.

Aperients are variable in effect and it may not be safe to give them before a diagnosis has been made because of the risk of aggravating such conditions as colitis or intestinal obstruction. A soap and water enema alone or followed by a bowel washout has three disadvantages; first, returning fluid often persistently floods the field of vision at sigmoidoscopy; second, the procedures may cause local discomfort or even damage to the rectum; third, the length of time involved in this method of preparation makes it impracticable for use in out-patient clinics. To clean out the loaded rectum through the sigmoidoscope by means of sucker, swabs, and forceps may be effective but is truly a Herculean task.

\section{PHARMACOLOGY}

A new synthetic laxative named Bisacodyl was reported upon by Schmidt (1953); its composition is

${ }^{1}$ Present address: Paddington General Hospital, Harrow Road, London, W.9.
(4,4' - diacetoxy - diphenyl) - (pyridil - 2) methane and it is marketed by Pfizer Ltd. as $5 \mathrm{mg}$. tablets or $10 \mathrm{mg}$. suppositories. Bisacodyl stimulates rapid localized contraction of smooth muscle when placed in contact with the mucous membrane of large bowel (Schmidt, 1953) acting upon mucosal nerve endings (Göing and Schaumann, 1955). The drug is not absorbed into the blood stream, it has no toxic effects, and it stimulates normal peristalsis to produce a stool of normal consistency (Schmidt, 1953).

The first clinical trials of Bisacodyl were reported concurrently by Förtsch (1953), Frankl (1953), and Barth (1953) using oral tablets with success for the treatment of patients with habitual constipation. Barth also found the tablets helpful in preparing some of his patients for barium enema examination. Schmidt had demonstrated that Bisacodyl had almost no effect upon small bowel, so the next step in its clinical development was the addition of Bisacodyl to the barium enema suspension (Schlegel, 1954). This stimulated large bowel peristalsis on $x$-ray screening and also aided subsequent elimination of the barium. The combined use of Bisacodyl tablets and suppositories in preparing patients for barium enema examinations has been favourably reported on by Hauff (1954), Kolshorn (1954), Keogh and Fraser (1958), and Sowerbutts (1960). A disadvantage of this combination of tablets and suppositories was that more patients failed to retain the barium enema during examination compared with the patients who were prepared by simple enema and bowel washout (Sowerbutts, 1960).

The purpose of this paper is to report on the use of Bisacodyl suppositories alone as immediate preparation of out-patients for sigmoidoscopy, and to compare this method with the older régime of an aperient and a simple enema in comparable groups of in-patients. 
Sigmoidoscopy was performed on 1,100 patients at St. Mary's Hospital, London, and the West Middlesex Hospital, Isleworth, between December 1957 and October 1960. The distribution of patients is summarized in Table $I$.

\section{TA BLE I}

SOURCES OF PATIENTS AND METHODS OF PREPARATION FOR SIGMOIDOSCOPY

Source No. of Patients Method of Preparation

\begin{tabular}{|c|c|c|c|}
\hline Out-patients & 600 & $\begin{array}{r}510 \\
90\end{array}$ & $\begin{array}{l}\text { No preparation } \\
\text { Bisacodyl suppository }\end{array}$ \\
\hline In-patients & 500 & $\begin{array}{l}250 \\
250\end{array}$ & $\begin{array}{l}\text { Aperient and soap and water enema } \\
\text { Bisacodyl suppository }\end{array}$ \\
\hline
\end{tabular}

OUT-PATIENTS The 600 cases in this group were unselected patients undergoing routine sigmoidoscopy on first attendance at afternoon rectal clinics and none had been specially prepared for this investigation. Good views were obtained on initial examination of 510 patients. In each of the other 90 patients the view was obscured by faeces and the sigmoidoscope was immediately withdrawn; one $10 \mathrm{mg}$. Bisacodyl suppository was then inserted in the rectum and the patient was allowed to leave the clinic. He was instructed to empty the bowel when the suppository acted and he was recalled to the clinic within 30 minutes. The sigmoidoscopy was then repeated at the same session. The laxative effect of the Bisacodyl suppository took place 10 to 25 minutes later in this series of patients.

IN-PATIENTS The 500 in-patients were divided into two equal groups regardless of age, diagnosis, or ward. Two hundred and fifty patients were each given an aperient (cascara gr. 2) on the eve of sigmoidoscopy and a soap and water enema early the next morning. The other 250 patients were each given a $10 \mathrm{mg}$. Bisacodyl suppository 45 to 120 minutes before sigmoidoscopy. It was decided to use some form of bowel preparation for all 500 in-patients because, first, admission to a hospital ward often alters a patient's bowel habits, and second, it would not be justifiable to prolong or repeat a general anaesthetic if the lower bowel were found to be loaded at sigmoidoscopy.

\section{RESULTS}

The results are summarized in Table II and Table III.

OUT-PATIENTS Sigmoidoscopy proved satisfactory in 510 patients without any preparation of the bowel. Of the remaining 90 patients who were re-examined after a Bisacodyl suppository, good views were obtained in 84 patients. Even after the bowel
SIGMOIDOSCOPIC VIEWS OBTAINED IN 600 OUT-PATIENTS WITH AND WITHOUT PREPARATION

\begin{tabular}{lrl} 
Method of Preparation & No. of Patients & $\begin{array}{l}\text { Sigmoidoscopic } \\
\text { View }\end{array}$ \\
\hline None & 510 & Good \\
Bisacodyl suppository (10 mg.) & 84 & Good \\
& 4 & $\begin{array}{c}\text { Excess of clear } \\
\text { mucus } \\
\text { facess of fluid } \\
\text { faeces }\end{array}$ \\
2 & &
\end{tabular}

${ }^{1}$ These two patients had ulcerative colitis.

TABLE III

SIGMOIDOSCOPIC VIEWS OBTAINED IN 500 IN-PATIENTS AFTER DIFFERENT METHODS OF PREPARATION

\begin{tabular}{lrrl} 
Method of Preparation & No. of Patients & $\begin{array}{l}\text { Sigmoidoscopic } \\
\text { View }\end{array}$ \\
\hline $\begin{array}{l}\text { Aperient and soap and water } \\
\text { enema }\end{array}$ & 250 & 217 & $\begin{array}{l}\text { Good } \\
\text { Faecal fluid and } \\
\text { enema solution }\end{array}$ \\
Bisacodyl suppository (10 mg.) & 250 & 242 & $\begin{array}{l}\text { Good } \\
\text { 'Faecal fluid }\end{array}$
\end{tabular}

${ }^{1}$ Five of these patients were found to have taken liquid paraffin or an aperient.

evacuation produced by a suppository the rectum was found to contain an excess of clear mucus in four patients. This mucus was readily removed by means of cotton wool swabs and it was thought that the mucus was the normal product of increased peristalsis since subsequent observations failed to reveal any organic disease of the bowel in these patients. In two patients with ulcerative colitis the rectum remained full of fluid faeces in spite of the Bisacodyl suppositories and prolonged swabbing and suction were necessary. However, there did not appear to be any increase in the inflammatory changes in rectal mucosa as a result of using suppositories in these two patients. Several patients experienced some discomfort or anxiety because a lavatory did not happen to be immediately available after they had been given Bisacodyl suppositories, but the problem was solved by suitable reservation of the appropriate facilities during subsequent rectal clinics. There were no side effects from the suppositories in contrast with Bisacodyl tablets, which have been reported to cause nausea and colic (Clark, 1957).

IN-PATIENTS Good views were obtained on sigmoidoscopy in 217 of the patients who had been prepared by an aperient (cascara gr. 2) followed by a soap and water enema. In the other 33 patients prepared in this way, however, the rectum in each case contained residual enema solution and needed to be cleaned by repeated swabbing and suction. 
Again, good views were obtained in 242 of the patients prepared by Bisacodyl suppositories alone. Sigmoidoscopy was obscured in eight patients and it was later found that five of these patients had taken liquid paraffin or an aperient the previous evening.

\section{DISCUSSION}

The use of Bisacodyl suppositories in preparation for sigmoidoscopy has advantages for all concerned and no disadvantages have been encountered. The method spares the patient the discomfort and even the occasional danger of injury from an enema, while children and nervous adults in particular are spared much emotional distress when suppositories are used. Patients who have experienced both methods of preparing the bowel on different occasions are unanimous in preferring suppositories.

The use of Bisacodyl suppositories affords the sigmoidoscopist swift and sure clearance of the lower bowel without producing any alteration in the appearance of the mucosa.

The suppositories save an enormous amount of nurses' time compared with the regimen of enemata and bowel washouts. The nursing staff was enthusiastic about the speed and simplicity of the method once assured of its effectiveness.

The use of Bisacodyl suppositories for the preparation of out-patients with laden bowels enabled the rectal clinics to proceed more smoothly. Another advantage was that the rectal clinic bookings were not overloaded by return visits simply because sigmoidoscopy was inadequate at the first visit.

\section{SUMMARY}

Methods of preparing the bowel have been surveyed in a series of 1,100 patients subjected to sigmoidoscopy. No preparation was necessary in most of the 600 out-patients. Bisacodyl (Dulcolax) suppositories were highly and rapidly effective in the rest. Of 500 in-patients, half were prepared in the traditional manner (enema after aperient) and half received the suppository three-quarters to two hours before the examination. It is concluded that the suppository method is easier and more effective for all patients.

I am grateful to Mr. H. H. G. Eastcott and to Mr. J. Scholefield for allowing me to investigate their patients at St. Mary's Hospital, and the West Middlesex Hospital, respectively.

I am also grateful to the medical department of the Boehringer Division of Pfizer Ltd., for supplying Bisacodyl suppositories and translations of some of the German papers.

\section{REFERENCES}

Barth, H. (1953). Klinisch-poliklinische Studien über ein neues Kontaktlaxativum. Dtsch. med. J., 4, 415-416.

Clark, A. N. G. (1957). A new evacuant suppository. Results in treatment of rectal dyschezia of chronic sick and geriatric patients. Brit. med. J., 2, 866-868.

Förtsch, A. (1953). Klinische Beobachtungen bei der Anwendung eines neuen Kontaktlaxativums in der Frauenheilkunde. Dtsch. med. Wschr., 78, 916-917.

Frankl, R. (1953). Die Behandlung der Obstipation bei Erkrankungen mit langer hiegedauer. Medizinische, 2, 1587-1588.

Göing, H., and Schaumann, W. (1955). Zum Nachweis reflektorisch von der Darmschleimhaut ans wirksamer Abführmittel. Arzneimittel-Forsch., 5, 282-285.

Hauff, F. W. (1954). Úber die Anwendung eines Kontaktlaxans als Suppositorium in der Chirurgie. Dtsch. med. J., 5, 483-484.

Keogh, R. K., and Fraser, R. G. (1958). Experiences with a new contact laxative in the preparation of the colon for radiological examination. J. Canad. Ass. Radiol., 9, 66-69.

Kolshorn, R. (1954). Obstipationsbehandlung und Röntgen-Vorbereitung mit Laxans-Suppositorien. Münch. med. Wschr., 96, 949-950.

Norbury, L. E. C. (1949). The Sigmoidoscope. Presidential address. Trans. med. Soc. Lond., 66, 226-241.

Schlegel, B. (1954). Darstellung der Colonschleimhaut und Motilitätsprüfung des Dickdarms mit Hilf verschiedener Kontaktlaxantien. Klin. Wschr., 32, 557-560.

Schmidt, L. (1953). Pharmakologie und Toxikologie einer neuen Klasse von Verbindungen mit laxierender Wirkung. Arzneimittel-Forsch., 3, 19-23.

Smiddy, F. G., and Goligher, J. C. (1957). Results of surgery in treatment of cancer of the large intestine. Brit. med. J., 1, 793-796.

Sowerbutts, J. G. (1960). Use of Bisacodyl in preparation of the bowels for a barium enema. Gut, 1, 175-177. 